\title{
Influence of HIP Sintering and Ce/La Additions on the Microstructure and Hardness on Inconel 718 Nickel-based Superalloy
}

H. M. Medrano-Prieto ${ }^{1}$, C.G. Garay-Reyes ${ }^{2}$, M.A. Ruiz-Esparza-Rodriguez ${ }^{2}$, Ivanovich Estrada ${ }^{3}$, J.C. Guía-Tello $^{2}$, Quirino Estrada ${ }^{1}$, J.M. Silva-Aceves ${ }^{1}$, J.S. Castro-Carmona ${ }^{1}$, H. Camacho-Montes ${ }^{1}$ and R. Martínez-Sánchez ${ }^{2}$

${ }^{1}$ Universidad Autónoma de Ciudad Juárez (UACJ), Ciudad Juárez, Chihuahua, Mexico, ${ }^{2}$ Centro de Investigación en Materiales Avanzados (CIMAV), Laboratorio Nacional de Nanotecnología, Chihuahua, Chihuahua, México, ${ }^{3}$ Centro de Investigacion en Materiales Avanzados SC, Chihuahua, Chihuahua, Mexico

The Inconel 718 superalloy, possess excellent properties to be employed in high-temperature applications, where its main characteristics are: high resistance to oxidation and good mechanical properties. Due to the mentioned above, it is employed in aeronautics and aerospace engines, nuclear power generation and petrochemical industry [1-3]. Recent researches on the effects and uses of rare-earth elements as rhenium, hafnium, tantalum, niobium, ruthenium among others, have increased to develop superalloys with higher properties than current ones. Important effects on microstructural and mechanical performance due to cerium and yttrium traces in this type of alloys have been reported, owing to these elements promote an increase in the lattice mismatch and the grain limit, as well as modification in carbides and eutectic phases. However, the use of cerium/lanthanum and a sintering process provided by Hot Isostatic Pressure (HIP) has not been deeply investigated in Inconel 718 superalloy, although studies indicate that the rare-earth elements additions and HIP sintering process are excellent candidates to improve the mechanical and microstructural properties [3-4]. The Inconel 718 alloyed with $\mathrm{Ce} / \mathrm{La}$ addition was processed by mechanical alloying (MA). A commercial Inconel 718 superalloy was used as raw material, and the mixture of rare-earth $(\mathrm{Ce} / \mathrm{La}-50 / 50)$ was taken with a purity of $99 \%$ to form alloys modified with contents of $0.1,0.2$ and $0.3 \mathrm{wt} \%$ of Ce/La. $5 \mathrm{~h}$ of milling time in a high-energy mill Spex 8000 was used to fabricate alloys. The milling device and milling media used were made from hardened steel. All millings runs were performed with N-heptane as process control agent and argon was used as an inert milling atmosphere. Powder mass $8.5 \mathrm{~g}$ and a ball-to-powder ratio of 5:1 were used. The compaction of the powders was carried out employing a hydraulic press under a uniaxial compaction pressure of $1.56 \mathrm{GPa}$ for 5 minutes. The sintering process was performed in an AIP6-30H HIP at $1200{ }^{\circ} \mathrm{C}$ for $4 \mathrm{~h}$ at 27000 psi under an argon atmosphere. The microstructural characterization was carried out in a transmission electron microscope HITACHI 7700, and the mechanical performance was evaluated in Vickers microhardness LM300 AT tester. Figure 1 corresponding to a STEM-EDS mapping shows the spatial distribution of $\mathrm{Ni}, \mathrm{Nb}, \mathrm{C}, \mathrm{Fe}$, $\mathrm{Cr}, \mathrm{Mo}, \mathrm{Ti}, \mathrm{Al}, \mathrm{Ce}$ and La elements in Inconel 718 superalloy modify with $0.3 \mathrm{Ce} / \mathrm{La}(\mathrm{wt} \%)$ in aged condition. This figure illustrates a refined microstructure composed for oxides, carbides and $\delta$-precipitates

$(\mathrm{Ni} 3 \mathrm{Nb})$ with acicular morphology, homogeneous distribution of $\mathrm{Ce}$ and rounded particles of La. In the hardness graph corresponding to Figure 2 is observed that the Ce/La additions in the Inconel 718 favor significant increments in the hardness values, in the sintered, solubilized and aged conditions. The maximum hardness obtained was in the aged alloy with $0.1 \mathrm{Ce} / \mathrm{La}(w t . \%)$. 


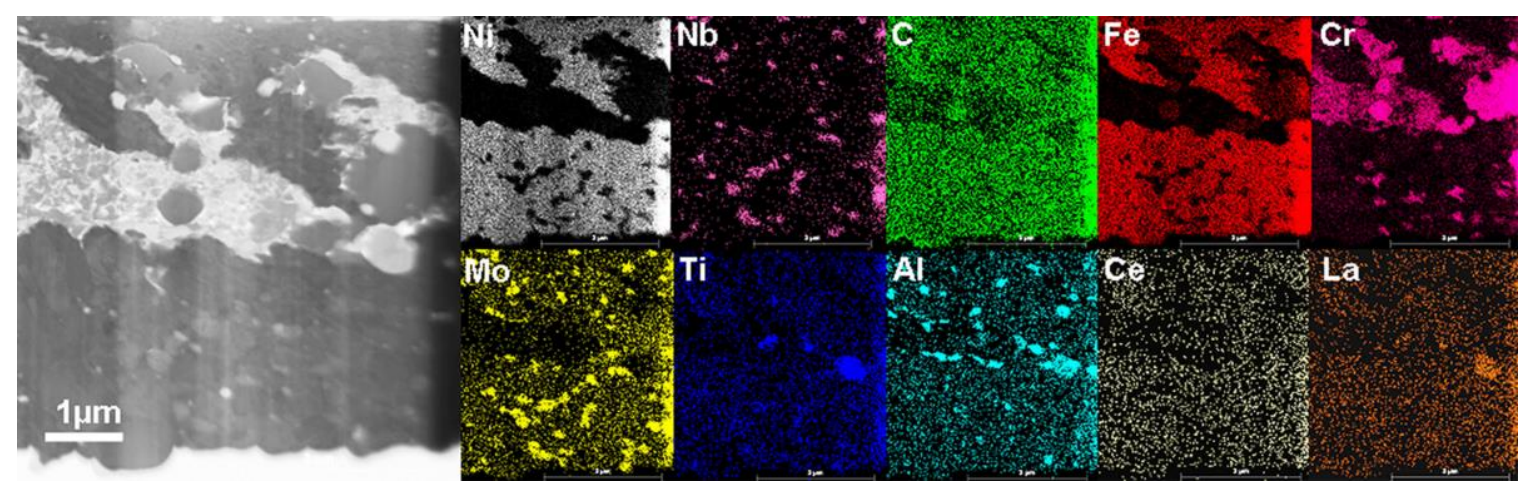

Figure 1. STEM Micrograph and its corresponding EDS analysis (map) of Inconel 718 with 0.3 Ce/La (wt. \%) addition.

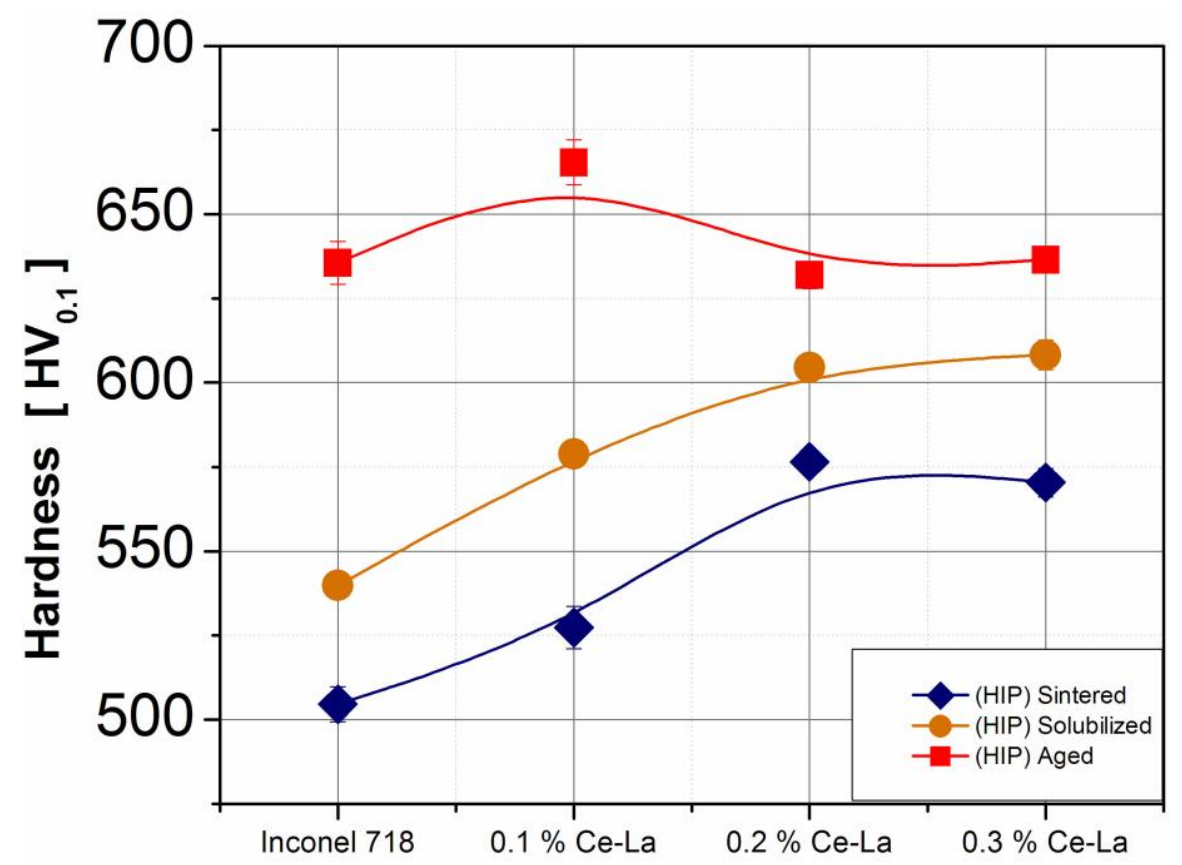

Figure 2. Vickers microhardness versus Inconel 718 and those modified with Ce/La additions, after sintered, solubilized, and aged conditions.

References

[1] E. Bassinia, V. Vola, M. Lorusso, R. Ghisleni, M. Lombardi, S. Biamino, D. Ugues, G. Vallillo, B. Picqué, Mater. Sci. Eng. A, 695 (2017) p. 55-65.

[2] Ming-Song Chen, Zong-Huai Zou, Y.C. Lin, Hong-Bin Li, Guan-Qiang Wang, Yan-Yong Ma, Mater. Charact, 151 (2019) p. 445-456.

[3] G. Appa Rao, M. Srinivas, D.S. Sarma, Mater. Sci. Eng. A, 418 (2006) p. 282-291.

[4] T. Baskaran, Shashi Bhushan Arya, Ceram. Int, 44 (2018) p. 17695-17708. 